\title{
Health Promotion Model: An Integrative Literature Review
}

\author{
Ibrahim Aqtam1, Muhammad Darawwad ${ }^{2}$ \\ ${ }^{1}$ Ministry of Health, Nablus, Palestine \\ ${ }^{2}$ School of Nursing, The University of Jordan, Amman, Jordan \\ Email: ibrahimaqtam@yahoo.com,m.darawad@ju.edu.jo
}

How to cite this paper: Aqtam, I. and Darawwad, M. (2018) Health Promotion Model: An Integrative Literature Review. Open Journal of Nursing, 8, 485-503. https://doi.org/10.4236/ojn.2018.87037

Received: July 3, 2018

Accepted: July 21, 2018

Published: July 24, 2018

Copyright (c) 2018 by authors and Scientific Research Publishing Inc. This work is licensed under the Creative Commons Attribution International License (CC BY 4.0).

http://creativecommons.org/licenses/by/4.0/

\section{c) (i) Open Access}

\begin{abstract}
Background: The Health Promotion Model (HPM) indicates that each person is a biopsychosocial creature that is partially shaped by the environment, but also seeks to create an environment in which inherent and acquired human potential can be fully expressed. The HPM is proposed as a holistic predictive model of health-promoting behavior for use in research and practice. Purpose: The purpose of this review is to examine how the HPM has been applied in various research studies. Methods: An integrative review was used to find studies that were guided by the HPM. Data search was between 2008 to 2018 using Google Scholar, Scopus, Web of Science, Science Direct, PubMed, Medline, CINAHL, EBSCO, Cochrane, ERIC, Joanna Briggs Institute and EBSCO host. The keywords used were Pender's and Health Promotion Model. Results: Seventeen studies were reviewed; most of them were quantitative studies. These studies discussed variables from the HPM. Most of the study variables were measured using instruments derived from the HPM. The results of the reviewed studies revealed that the HPM had predictive value in estimating health-promoting behaviors. Conclusion: The HPM was widely established in the nursing community and was implemented in nursing practice, education, and research. In addition, the HPM constructs were used to hypothesize conceptual frameworks in many studies to predict health-promoting behaviors in many chronic diseases.
\end{abstract}

\section{Keywords}

Pender's and Health Promotion Model, Health Promoting Behaviors, Women, Children, Workers, and Students

\section{Introduction}

The Health Promotion Model (HPM) was created by Pender in 1982 and was 
revised in 1987, 1996, and 2002. Pender's background in nursing, human development, experimental psychology, and education led her to use a holistic nursing perspective, social psychology, and learning theory as foundations for the HPM [1]. The Health Promotion Model (HPM) provides a framework to explain and predict specific health behaviors [2]. The HPM shows that each person is a biopsychosocial creature that is partially shaped by the environment, but also seeks to create an environment in which inherent and acquired human potential can be fully expressed [3]. The HPM was originally developed to target individuals; however the framework can be used to target families, groups, or communities. The HPM comprises three primary areas that nurses can use to assess health promotion behaviors: 1) personal characteristics and experiences; 2) behaviors-specific cognition and affect; and 3) behavioral outcome. Moreover, the HPM incorporates elements of the change process, including a commitment to a plan of action and acknowledgement of competing demands. The final outcome is engagement in health promotion behaviors [4]. Pender puts her efforts to develop a model that guide nursing society as a whole through interactions at the individual level and biophysical processes that motivate individuals to participate in health-promoting behaviors leading to overall well-being [3]. Pender's model provides important guides for nursing professionals as they focus on health promotion strategies for patients and for research aimed at prediction of health-promoting behaviors. Finally, HPM has been tested in different populations and settings. Furthermore, it was widely accepted by the nursing community and is currently used in nursing practice, research and education [5]. For this reason, this literature review comes to examine how the HPM has been applied in various research studies.

\section{Methods}

\subsection{Search Strategy}

In this review, the search was performed by different international databases including Google Scholar, Scopus, Web of Science, Science Direct, PubMed, Medline, CINAHL, EBSCO, Cochrane, ERIC, Joanna Briggs Institute and EBSCO host using the keywords of "Health Promotion Model", "Health-Promoting Behaviors", "Women's", "Children", "Workers", and "Students". Initially, separated with each new search added a new keyword until including all keywords. Later, these words were searched in combination with each other, starting with search process targeted primary resources with no geographical limits and targeted disciplines other than nursing such as psychology, public health, and social works. Boolean operators (AND, OR) have been applied separately and in combination with the keywords to expand, combine, or exclude keywords in a search to narrow down the results and reach a more focused and productive results. Articles excluded from search those that focus on populations not comparable to nurses and articles published in languages other than English. However, the searching process was limited to following inclusion criteria: 1) the article was 
published in a peer-reviewed nursing journal; 2) HPM was the conceptual framework or one of the conceptual frameworks that guided the study; 3) the study was research based; 4) full text article was present; 5) article was published in English language; and 6) articles published between 2008 and 2018.

\subsection{Overview of the Reviewed Studies}

The electronic search revealed 40 articles; 23 articles were excluded because they were non research-based articles or were not published in a peer-reviewed nursing journal. The 17 research studies that met the inclusion criteria were retrieved and reviewed, where 16 of them used quantitative research methodologies [6]-[21], and one used qualitative methodology [22]. Cross-sectional research design was the most commonly used design in the quantitative studies, and two studies used quasi experimental design [18] [20], and one study used a randomized clinical trial [10] (See Figure 1).

\subsection{The Purposes of the Reviewed Studies}

There were wide variations in the purposes of the reviewed studies. Generally, the purposes of these studies can be categorized into two main categories. The first category is the studies that described aspects of the HPM in different populations, while the second category is the studies that tested relationships either among different variables of HPM, or between selected HPM variables and other variables.

The first category included six studies which described the everyday physical activity habits of students and analyzed the practice of physical activity and its determinant [6], identified and documented factors influencing the Intermittent Preventive Treatment (IPTp2) in pregnancy + uptake [12], examined facilitators

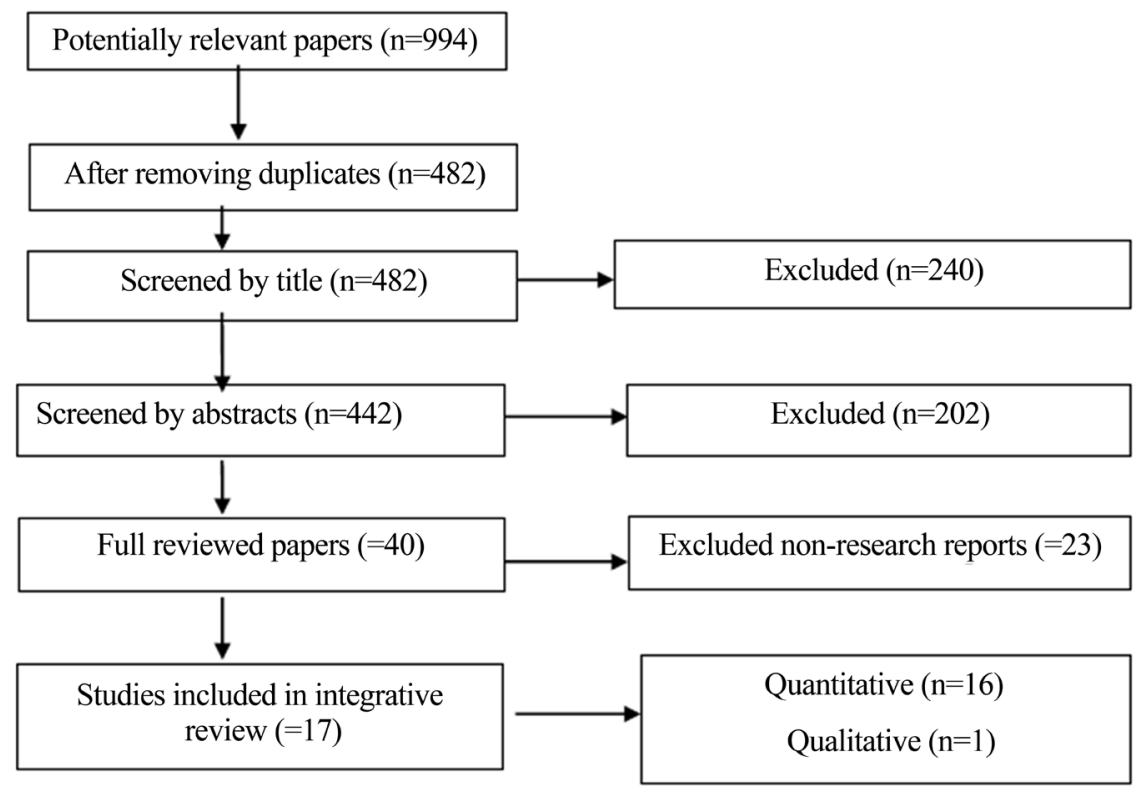

Figure 1. Search strategy and outcomes. 
and barriers that migrant women in Turkey identified related to breast self-examination, clinical breast examination, and mammography [22], determined health promoting behaviors of university students in Jordan and factors influencing them [15], determined the knowledge of and compliance with standard precautionary measures among nurses in Madonna University Teaching Hospital [17], and examined the factors that may influence health responsibility, relationships, resilience, neighborhood perception, social support, and health promoting behaviors in adolescents, between the ages of 13 and 18 years old [21]. All these studies contributed to understanding the application of HPM in different populations.

The second category included eleven studies which evaluated the HPM as a mean to predict physical activity (PA) in a sample of Iranian adolescent boys [7], compared perceived self-efficacy, exercise benefits, exercise barriers, and commitment to exercise between patients diagnosed with osteoporosis and osteoarthritis, and assessing the influence of perceived exercise self-efficacy, exercise benefits, and barriers on commitment [8], explored perceived exercise self-efficacy, benefits and barriers, and commitment to exercise among Jordanians with chronic illnesses [14], explored perception of exercise benefits and barriers among Jordanian patients' with End Stage Renal Disease (ESRD) [11], used HPM to provide insight into the relationship between dietary and fluid non-adherence, depressive symptoms, quality of life, perceived barriers and benefits of exercise, and perceived social support among Jordanian patients with ESRD receiving hemodialysis [9], conducted an evaluation of an educational program based on the HPM and stages of change to improve physical activity (PA) behavior among Iranian adolescents [10], used Pender's HPM to describe and identify the predictors of health-promoting behaviors in Nepalese migrant workers in Korea [13], examined the psychometric properties of the Arabic version of Bandura's Exercise Self-Efficacy scale (ESE-A) among Jordanian patients with different chronic diseases [16], assessed the effect of application of Pender's HPM on management of hypertension among adults in rural area [18], examined the impact of performing a HPM intervention on physical activity of the health Volunteers [19], and investigated the effect of Pender's HPM to improve the nutritional behavior of overweight and obese women admitted to Fatemiyeh Hospital clinics in Hamadan, Iran [20]. All these studies tested relationships among different variables of the HPM. Those studies revealed that testing relationships among different variables of the HPM will enhance the predictive ability of this model in predicting the health-promoting behaviors.

\subsection{Sample of Populations}

Different samples and populations were used in the reviewed studies. Generally, the samples and populations of these studies can be categorized into four categories. The first category is the studies that recruited students with different level of education, 79 students in a public school [6], 515 boys from 100 junior high 
and high schools [7], 165 adolescents aged 13 - 15 years old from high schools [10], 525 university students receiving education from two governmental and one private universities [15], and 122 adolescents students between the ages of 13 and 18 years old [21]. The second category is the studies that tested a samples and populations of chronic illness. The samples were 75 patients with a clinical diagnosis of osteoporosis and 75 patients with osteoarthritis [8], 190 patients with ESRD receiving hemodialysis [9], 190 patients with ESRD [11], 402 outpatient with chronic illnesses [14], 272 patients with chronic illness [16], and 150 adults with hypertension [18].

The third category is the studies that target women with different health status. The samples were 278 pregnant women who were at the 24 th week or more of gestation, aged between 15 and 49 years [12], 39 women who were older than 20 years [22], and 108 overweight women [20]. The last category is the studies that involved workers from different background. The samples were $169 \mathrm{immi}-$ grant workers [13], 102 nurses working in Madonna University Teaching Hospital [17], and 80 health volunteers [19]. It can be noticed that studies involved a wide range of populations with different sample sizes in different settings. Using such different populations and settings indicated that the HPM is applicable and highly generalizable.

\subsection{The Key Variables}

Many variables and concepts have been comprehensively discussed in the reviewed studies. Most of these variables are components of the HPM. Some studies discussed one or two variables. For example, some studies described the physical activity of students and its determinants [6], identified factors influencing preventive treatment in pregnancy [12], determined health promoting behaviors among university students [15], determined the knowledge of and compliance with standard precautionary measures among nurses [17], and evaluated exercise self-efficacy among Arabic patients with chronic diseases by assessing the psychometric properties of the Arabic version of Exercise Self-Efficacy scale (ESE-A) [16].

While other studies discussed more than two variables utilized from HPM. For example, some studies evaluated the HPM concepts (perceived benefits, perceived barriers, exercise self-efficacy, enjoyment of PA, social support, and exposure to modeling, interpersonal norms, commitment to PA planning, competing demands) as a means to predict PA [7], compared perceived self-efficacy, exercise benefits, exercise barriers, and commitment to exercise between patients diagnosed with osteoporosis and osteoarthritis, and assessing the influence of perceived exercise self-efficacy, exercise benefits, and barriers to commitment [8], used HPM and its stages of change to improve PA behavior among adolescents [10], examined the impact of performing HPM intervention on PA of the health volunteers [19], and used HPM to examine relationship between dietary and fluid non adherence, depressive symptoms, quality of life, perceived barriers 
and benefits of exercise, and perceived social support among patients with ESRD [9]. Moreover, some studies explored perception of exercise benefits and barriers along with the factors associated with such perceptions among patients with ESRD [11], assessed the relationship between perceived exercise self-efficacy, benefits and barriers, and commitment to exercise planning [14], used HPM to describe and identify the predictors of health-promoting behaviors among migrant workers [13], and examined facilitators and barriers that migrant women identified related to breast self-examination, clinical breast examination, and mammography [22]. Furthermore, some studies assessed the effect of application of HPM on management of hypertension among adults [18], investigated the effect of HPM to improve the nutritional behavior of overweight and obese women [20], and examined relationships among health responsibility, resilience, neighborhood perception, social support, and health promoting behaviors in adolescents [21].

Testing relationships among variables of the HPM or with other variables in different settings and using different populations is very important in exploring and validating the relationships and will enhance the predictive value of the HPM.

\subsection{Data Collection Methods}

Self report method was used in all of the studies as a data collection method. Specifically, self administered questionnaires were used in most of the reviewed studies. However, one study used interview for data collection [22], and other studies used several techniques to collect data such as self reported questionnaire, observation, anthropometric evaluation, and measuring blood pressure [6] [18].

\subsection{Measuring Instruments}

Many instruments were used for data collection. The review of these studies revealed that all of the research instruments used were derived from the HPM. These instruments included Pender's Health-Promoting Behavior Scale, Pender's Commitment to a Plan of Action Scale, Pender's Perceived Benefits Scale, Pender's Perceived Barriers to Action Scale, and Pender's Preference Scale. All used instruments are presented in (Appendix A).

\section{Results}

The reviewed studies examined HPM in different settings, populations, and circumstances. So, the results of each study are relatively unique and can be generalized to people who share the same characteristics of the study population. One study found that the first component "previous behaviors and personal factors" of Pender's theoretical model of health promotion can be related to the daily routine of children and adolescents, focusing on physical activities [6]. While, another study showed that, the HPM accounted for $37 \%$ of the variance in Phys- 
ical Activity (PA) but did not represent a good data fit, there were significant pathways between PA and self-efficacy, enjoyment, and PA modeling, the revised model that included the indirect effects of competing demands explained $34 \%$ of the variance in PA and represented a good data fit, and self-efficacy, commitment to planning, and enjoyment were linked to PA. Additionally, competing demands have an effect on PA [7].

Moreover, another study revealed that osteoporotic patients had significantly higher mean scores of commitment to plan, and higher exercise self-efficacy, while the mean score of exercise benefit was higher in the osteoarthritis group. In addition, a significant positive correlations were found between commitment and perceived self-efficacy scores, and between self-efficacy and perceived lack of barriers and exercise benefits in both groups, age was a negative predictor for commitment in osteoporosis group, while self-efficacy and lack of barriers were positive predictors, and in osteoarthritis group, self-efficacy was the only positive predictor of commitment [8]. A different study among ESRD patients showed full commitment to diet guidelines and to fluid guidelines, depression had significant negative association with quality of life, and the results also revealed a predictive model of only two variables: age and residual renal function for dietary non-adherence [9]. A similar population with different variables study revealed that participants had significantly perceived more exercise benefits compared with exercise barriers [11].

Furthermore, a significant correlation has been found between commitment to exercise planning with barriers and benefits among chronically ill patients, and self-efficacy was not correlated with other variables [14]. From the other side, exercise self-efficacy among patients with different chronic illnesses was evaluated by assessing the psychometric properties of the Arabic version of Exercise Self-Efficacy scale (ESE-A), the results showed significant correlation with weekly exercise frequency, duration, and evaluation of physical exercise, and the ESE-A was found to be a fit measure to evaluate exercise self-efficacy among Arabic patients with chronic diseases [16].

Nevertheless, differences in all HPM constructs, except activity-related affect and social influences, were significant between baseline and follow-up measurements, adolescents in the intervention as compared to the control group were placed in action (70\%) or preparation (30\%) stages at follow-up, and the results revealed that competing preferences, social norms, role models, and commitment to action plan can significantly predict PA behavior, and the model accounted for $22.5 \%$ of the variance in PA [10]. Moreover, a group of pregnant women aged between 15 and 49 years coming to public health facilities to identify and document factors influencing the Intermittent Preventive Treatment in pregnancy (IPTp2) + uptake, the results indicated that $37.2 \%$ participants who had obtained less than IPTp2 and 53.5\% who accessed IPTp2+ reported receiving support from their partners towards Antenatal Care (ANC) visits, and the relationship between the uptake of IPTp services and self-reported risk-perception 
was not significant, also the relationship between the uptake of IPTp and perceived seriousness of malaria infection during pregnancy was not significant, while perception about the duration suggesting up to $95 \%$ chance that the uptake of IPTp significantly associated with the duration taken at the health facilities before receiving services, and the attitude of most providers at the ANC facilities $99 \%$ chance that the uptake of IPTp significantly associated with perceived attitudes of providers towards pregnant women attending ANC clinics ( $P$ $=0.000)[12]$.

Another study identified predictors of health-promoting behaviors among 169 workers, the results revealed that spiritual activity was the highest reported health-promoting behavior, whereas physical activity was the least practiced behavior, and self-efficacy was the only significant predictor of health-promoting behavior [13]. Furthermore, in a sample of 525 university students receiving education from two governmental and one private universities in Jordan, a significant differences found between health-promoting behavior and student's age, gender, employment status, family income, university type, and faculty type, also significant differences found between males and females on health responsibility and interpersonal relations, stress management, and spiritual growth [15]. From the other side, a study based on HPM to direct health protection among 102 nurses working in teaching hospital, found that knowledge of respondents and their compliance with standard precautionary measures was above average. The majority of the nurses (80\%) comply with both medical and surgical asepsis [17].

A different study aimed to assess the effect of application of HPM on management of hypertension among 150 adults in Egypt, showed that there was statistical significant improvement among the study group than the control group at the posttest of health-promoting behavior, and the highest mean score was in the posttest of nutrition dimension followed by medication adherence, stress management and physical activity, but smoking had no statistical significant improvement [18]. Moreover, a significant difference among 80 health volunteers in Iran found between the mean scores of physical activity and other structures of HPM in the experimental group after the intervention and its score before intervention [19]. Nevertheless, an experimental study to investigate the effect of Pender's HPM in improving the nutritional behavior of 108 overweight and obese women visits hospital clinics in Iran, showed significant differences in the experimental group before and after the intervention in nutritional behavior, perceived benefits, perceived self-efficacy, commitment to action, interpersonal and situational influences, behavior-related affect, and perceived barriers [20].

In another correlation study to examine the relationships between health responsibility, social support, resilience, neighborhood perception, and health behaviors among 122 adolescents between the ages of 13 and 18 years old, the results found a significant relationships between health responsibility and health promoting behaviors and between health responsibility and neighborhood perception, also no relationships were found between the dependent variable of 
health responsibility and the independent variables of resilience and social support in this population [21].

Finally, a qualitative study used an interview guided by the Health Belief Model (HBM) and the Health Promotion Model (HPM) to examine facilitators and barriers among 39 women in Turkey related to breast self-examination, clinical breast examination, and mammography. Three main themes were emerging: 1) knowledge and awareness about breast cancer; 2) personal factors; and 3) medical service provider and social environment. Also the results showed that HBM and HPM were effective in explaining barriers and facilitators toward participation of women in screening behaviors. Additionally, lack of information, indifference, and cultural factors are the most important barriers of women [22].

\section{Discussion}

This integrative literature review showed that Pender's HPM can be used for conducting studies that predict effective benefits/barriers in health-promoting behaviors, detect impacts of intervention for improving health-promoting behaviors, test this model, predict stage or level of change in related factor affecting health-promoting behavior, and to determine the relationship of variables associated with health-promoting behaviors.

The studies predicting effective benefit/barriers and the significant determinants of health-promoting behaviors emphasized the fact that according to Pender's model, healthcare providers/professionals can understand and address modifiable behavior-specific variables [23]. Therefore, they are ready to identify health benefits/barriers and recommend health-promoting behaviors guidance and social support to all people. Also, they should consider these variables in interventions to increase healthy lifestyle. Applications of Pender's model guide the development of successful theory-based interventions and provided evidence of the effectiveness of several interventions based on this theory. Moreover, HPM is useful in decreasing risk factors of diseases, especially chronic diseases and symptoms, and promote healthy lifestyle [24].

Finally, identifying health-promoting behavior and predicting stage of change related factors can affect health-promoting behavior, so HPM can be very useful, especially to examine the similarities and differences among groups, and healthcare providers can use these similarities and differences to assess, identify and use effective health-promotion programs, strategies and interventions [25].

\section{Conclusion}

The HPM has become prevalent in later years and might be practical in understanding health-promoting behaviors. Such integrated review showed that HPM is valid and applicable in different nursing settings. Direct or indirect influences of HPM predictors on health-promoting behaviors have been confirmed in this paper. Such an integrative review paper approves that HPM provides a frame- 
work to understand the factors and variables that influence the initiation of health-promoting behaviors in different settings with different populations. This paper shows that the effective use of evidence-based research in nursing practice requires an integrated review such as our review paper.

\section{Conflicts of Interest}

The authors declare no conflicts of interest regarding the publication of this paper.

\section{References}

[1] Sakraida, T.J. (2013) The Health Promotion Model. In: Alligood, M.R. and Marriner Tomey, A., Eds., Nursing Theorists and Their Work, 8th Edition, Chapter 21, Mosby Elsevier, St. Louis.

[2] McEwen, M. and Wills, E.M. (2011) Theoretical Basis for Nursing. Wolters Kluwer/Lippincott Williams \& Wilkins, Philadelphia.

[3] Pender, N.J., Murdaugh, C. and Parsons, M.A. (2011) Health Promotion in Nursing Practice. 6th Edition, Pearson, Boston.

[4] Walker, S.N., Sechrist, K.R. and Pender, N.J. (1987) The Health-Promoting Lifestyle Profile: Development and Psychometric Characteristics. Nursing Research, 36, 76-80. https://doi.org/10.1097/00006199-198703000-00002

[5] Marriner-Tomey, A. and Alligood, M.R. (2006) Nursing Theorists and Their Work. 6th Edition, Mosby/Elsevier, St. Louis.

[6] Guedes, N.G., Moreira, R.P., Cavalcante, T.F., Araujo, T.L. and Ximenes, L.B. (2009) Students' Physical Activity: An Analysis according to Pender's Health Promotion Model. Revista da Escola de Enfermagem da USP, 43, 744-780.

https://doi.org/10.1590/S0080-62342009000400006

[7] Taymoori, P., Lubans, D. and Berry, T. (2010) Evaluation of the Health Promotion Model to Predict Physical Activity in Iranian Adolescent boys. Health Education \& Behavior, 37, 84-96. https://doi.org/10.1177/1090198109356407

[8] Hanan, S.A. and Sahar, Y.M. (2011) Perceived Self-Efficacy and Commitment to an Exercise Plan in Patients with Osteoporosis and Osteoarthritis. Journal of American Science, 7, 315-323.

[9] Khalil, A.A., Darawad, M.W., Al-Gamal, E., Hamdan-Mansour, A.M. and Abed, M. (2012) Predictors of Dietary and Fluid Non-Adherence in Jordanian Pattients with End-Stage Renal Disease Receiving Hemodialysis: A Cross-Sectional Study. Journal of Clinical Nursing, 22, 36-127.

[10] Sanaeinasab, H., Saffari, M., Pakpour, A., Nazeri, M. and Piper, C. (2012) A Model-Based Educational Interventionto Increase Physical Activity among Iranian Adolescents. Jornal de Pediatria, 88, 430-438. https://doi.org/10.2223/JPED.2223

[11] Darawad, M.W. and Khalil, A.A. (2013) Jordanian Dialysis Patients' Perceived Exercise Benefits and Barriers: A Correlation Study. Rehabilitation Nursing. The Official Journal of the Association of Rehabilitation Nurses, 38, 22-315.

[12] Mutulei, A.C.N. (2013) Factors Influencing the Uptake of Intermittent Preventive Treatment for Malaria in Pregnancy: Evidence from Bungoma East District, Kenya. American Journal of Public Health Research, 1, 110-123. https://doi.org/10.12691/ajphr-1-5-2

[13] Bhandari, P. and Kim, M. (2016) Predictors of Health Promoting Behaviors of Ne- 
palese Migrant Workers. The Journal of Nursing Research, 24, 232-239.

[14] Darawad, M.W., Khalil, A.A., Hamdan-Mansour, A.M. and Nofal, B. (2014) Perceived Exercise Self-Efficacy, Benefits and Barriers, and Commitment to a Plan for Exercise among Jordanians with Chronic Illnesses. Rehabilitation Nursing. The Official Journal of the Association of Rehabilitation Nurses, 41, 342-351.

[15] Shaheen, A.M., Nassar, O.S., Amre, H.M. and Hamdan-Mansour, A.M. (2015) Factors Affecting Health-Promoting Behaviors of University Students in Jordan. Health, 7, 1-8. https://doi.org/10.4236/health.2015.71001

[16] Darawad, M.W., Hamdan-Mansour, A.M., Khalil, A.A., Arabiat, D., Samarkandi, O.A. and Alhussami, M. (2016) Exercise Self-Efficacy Scale: Validation of the Arabic Version among Jordanians with Chronic Diseases. Clinical Nursing Research, 1, $1-17$.

[17] Grace, C.R. and Sandra, E.I. (2016) Knowledge and Compliance with Standard Precautionary Measures among Nurses in Madonna University Teaching Hospital, Elele, Rivers State. International Journal of Nursing Didactics, 6, 21-26.

[18] Hussein, A.A., Abd El Salam, E.A. and Amr, E.F. (2016) A Theory Guided Nursing Intervention for Management of Hypertension among Adults at Rural Area. Journal of Nursing Education and Practice, 7, 66-78. https://doi.org/10.5430/jnep.v7n1p66

[19] Rahimian, M., Mohammadi, M., Mehri, A. and Rakhshani, M. (2016) Impact of Performing Health Promotion Model Intervention on Physical Activity of Health Volunteer of Torbat-e-Jam City, Iran. International Archives of Health Sciences, 3, 87-91. https://doi.org/10.18869/IAHS.3.3.87

[20] Khodaveisi, M., Omidi, A., Farokhi, S. and Soltanian, A.R. (2017) The Effect of Pender's Health Promotion Model in Improving the Nutritional Behavior of Overweight and Obese Women. International Journal of Community Based Nursing and Midwifery, 5, 165-174.

[21] Ayres, C.G. and Pontes, N.M. (2018) Use of Theory to Examine Health Responsibility in Urban Adolescents. Journal of Pediatric Nursing, 38, 40-45. https://doi.org/10.1016/j.pedn.2017.09.011

[22] Tuzcu, A. and Bahar, Z. (2014) Barriers and Facilitators to Breast Cancer Screening among Migrant Women within Turkey. Journal of Transcultural Nursing, 26, 47-56. https://doi.org/10.1177/1043659614526245

[23] Ho, A.Y., Berggren, I. and Dahlborg-Lyckhage, E. (2010) Diabetes Empowerment Related to Pender's Health Promotion Model: A Meta-Synthesis. Nursing \& Health Sciences, 12, 259-267. https://doi.org/10.1111/j.1442-2018.2010.00517.x

[24] Kim, S.J. and Yoo, I.Y. (2016) Health Promotion Behavior of Chinese International Students in Korea Including Acculturation Factors: A Structural Equation Model. Asian Nursing Research, 10, 25-31. https://doi.org/10.1016/j.anr.2015.10.008

[25] Heydari, A. and Khorashadizadeh, F. (2014) Pender's Health Promotion Model in Medical Research. The Journal of the Pakistan Medical Association, 64, 1067-1074. 


\section{Appendix A: Studies Guided by Health Promotion Model $(n=17)$}

\begin{tabular}{|c|c|c|c|c|c|c|}
\hline Citation & Purpose & Design & Key Variables & Instruments & $\begin{array}{c}\text { Study } \\
\text { Populations }\end{array}$ & Results \\
\hline
\end{tabular}

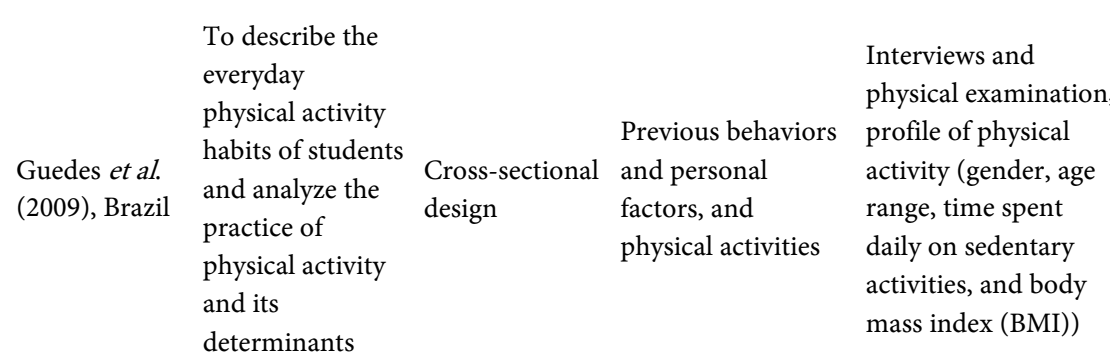

To evaluate the

Taymoori et al. (2010),

Iran
Physical activity

Cross-sectional and psychosocial variables,

Competing demands
HPM as a means

to predict

physical activity

(PA)
Physical activity and psychosocial

variables-a modified version of the child/adolescent activity log (CAAL; Garcia, et al., 1995, 1997), Competing demands-Pender's scale
The first component "previous behaviors and personal factors" of 79 children and adolescents aged 6 to 18 years in a public school in Brazil Pender's theoretical model of health promotion can be related with the daily routine of children and adolescents, focusing on physical activities

HPMHPM accounted for $37 \%$ of the variance in Physical Activity (PA) but did not represent a good data fit. There were significant pathways between PA and self-efficacy, enjoyment, and PA modeling respectively $(B=0.25, P<$ $0.001),(B=0.22, P<$ $0.01)$, and $(B=-0.13, P<$ 0.05). A revised model 515 boys from 100 junior high and high schools in Iran that

included the indirect effects of competing demands explained 34\% of the variance in PA and represented a good data fit. In the revised model, self-efficacy, commitment to planning, and enjoyment were associated with PA; additionally, competing demands influence PA 
To compare

perceived

self-efficacy,

exercise benefits,

exercise barriers,

and commitment

to exercise

Hanan, S.A. between patients and Sahar Y.M. diagnosed with

(2011), Egypt osteoporosis and osteoarthritis, and

to assess the

influence of

perceived exercise

self-efficacy,

exercise benefits,

and barriers on

commitment
To provide

insight into the

relationship

between dietary

and fluid

nonadherence,

depressive

symptoms, quality A descriptive,

Khalil et al. of life, perceived correlational,

(2012), Jordan barriers and

benefits of

exercise, and

perceived social

support among

patients with

end-stage renal

disease receiving

hemodialysis
Perceived

self-efficacy-perceive

d exercise self-efficacy

scale, Bandura (1997),

Perceived benefits and barriers to

Perceived exercise-exercise

Comparative cross-sectional design

self-efficacy, exercise benefits and barriers

benefits, exercise

barriers, and

commitment to a

plan

scale Sechrist, et al.

(1987), Commitment

to a plan-commitment

to a plan for exercise

scale, Pender (1996),

and adherence to the

exercise-exercise

documentation record

(developed by the

researchers)

Diet and fluid

non-adherence-the

dialysis diet and fluid

nonadherence

questionnaire

(DDFQ), (Vlaminck,

et al., 2001),

Depressive

symptoms-the beck

depression

inventory-II (BDI-II),

Dietary and fluid

(Beck, et al., 1996),

nonadherence,

depressive

symptoms, quality

of life, perceived

Perceived quality of

life-the quality of life

index (QLI), (Ferrans

\& Powers, 1985),

barriers and benefits Perception of dialysis

of exercise, and

perceived social

support

patients regarding

exercise benefits and

barriers-the dialysis

patient-perceived

exercise benefits and

barriers scale

(DPEBBS), (Zheng,

et al., 2009), and

perceived social

support-the

multidimensional

perceived social

support scale (Zimet,

et al., 1988)

Osteoporotic patients had significantly of commitment to plan and exercise self-efficacy, while exercise benefit was higher in the osteoarthritis group $(P<0.001)$. In addition, significant positive correlations were found

75 patients with a clinical diagnosis of osteoporosis and 75 patients with osteoarthritis at the Maternity Hospital, and Ain Shams University Hospitals in Egyp between commitment and perceived self-efficacy scores, and between self-efficacy and perceived lack of barriers and exercise benefits in both groups $(P<0.001)$. Age was a negative predictor for commitment in osteoporosis group, while self-efficacy and lack of barriers were positive predictors. In osteoarthritis group, self-efficacy was the only positive predictor of commitment

A convenience sample of 190

patients diagnosed with ESRD and being dialyzed in three major cities in Jordan: Amman, Zarqa and Irbid
ESRD patients showed full commitment to diet guidelines and to fluid guidelines. Depression had significant negative association with quality of life (importance and satisfaction) $(r=-0.60, r=$ $-0.32, P=0.001$, respectively). Results also revealed a predictive model of only two variables: age $(B=-0.22, P=0.05)$ and residual renal function for dietary non-adherence ( $B$ $=-0.23, P=0.012$ ) 


\section{Continued}

To explore

perception of

exercise benefits

Darawad et al. and barriers

(2013), Jordan among

Jordanian

patients' with

ESRD
Descriptive correlational design

To explore perceived exercise self-efficacy,

Darawad et al. benefits and (2014), Jordan barriers, and commitment to exercise among Jordanians with chronic illnesses

To examine the psychometric properties of the Arabic version of Bandura's

Darawad et al. Exercise (2016), Jordan Self-Efficacy scale (ESE-A) among Jordanian patients with different chronic diseases.

Descriptive design

\section{Descriptive} design
Perception of dialysis patients regarding exercise benefits and barriers-the dialysis

Perceived exercise benefits and barriers patient-perceived exercise benefits and barriers scale (DPEBBS), (Zheng, et al., 2009).

Perceived benefits and barriers-the exercise benefits and barriers Scale (EBBS),

(Sechrist, Walker, \&

Perceived exercise Pender, 1987), self-efficacy, $\quad$ Exercise benefits and barriers, and commitment to exercise planning cross-sectiona cross-sectional Exercise self-efficacy self-efficacy-the exercise self-efficacy Scale (ESE), (Bandura, 2006), and commitment to exercise planning -the commitment to a plan for exercise scale, (Bandura, 2006) -frequency, duration,
A convenience sample of 190 patients

diagnosed with Participants significantly ESRD ages ranged perceived more exercise from 18 - 84 and benefits compared with being dialyzed in exercise barriers $(\mathrm{t}=2.17$, three major cities $\mathrm{df}=187, P=0.03$ )

in Jordan:

Amman, Zarqa and Irbid
A convenience sample of 402 ages ranged from 19 - 93 years with chronic illnesses from four hospitals representing the main healthcare sectors in Jordan governmental, teaching, and private
Exercise profile (frequency, duration, exercise activity, and health perception) and exercise activity-researcher developed, and health perception -(Mason-Hawkes \& Holm, 1993), and Exercise self-efficacy-the Arabic version of exercise self-efficacy scale (ESE-A), (Bandura, 1997)
A convenience sample of 272 patients with chronic illness from outpatient clinics (cardiac, endocrine, and renal) at four hospitals representative for the major health care sectors in Jordan: public, university -affiliated, and private
Significant correlation between commitment to exercise planning with barriers and benefits among chronic ill patients $(r=0.1, r=0.10, P=$ 0.001 , respectively). Self-efficacy was not correlated with other variables
Significant correlation with weekly exercise frequency $(r=0.23, P<$ $0.001)$, duration $(r=0.31$, $P<0.001$ ), and evaluation of their physical exercise ( $r$ $=0.39, P<0.001)$. Also the ESE-A was found to be a fit measure to evaluate exercise self-efficacy among Arabic patients with chronic diseases (Cronbach's alpha was 0.89 and split-half coefficient was 0.83 ) 


\section{Continued}

\begin{tabular}{|c|c|}
\hline \multirow{11}{*}{$\begin{array}{l}\text { Sanaeinasab } \\
\text { et al. (2012) }\end{array}$} & To evaluate of an \\
\hline & educational \\
\hline & program based \\
\hline & on the health \\
\hline & promotion \\
\hline & model (HPM) \\
\hline & and stages of \\
\hline & change to \\
\hline & improve physical \\
\hline & activity (PA) \\
\hline & behavior \\
\hline
\end{tabular}

To evaluate of an program based on the health and stages of improve physical behavior
Physical

activity - stage of

changes scale,

Kearney, et al. (1999), ability to

exercise-children's

exercise self-efficacy survey, Garcia et al. (1995), perceived benefits/barriers to exercise-children's perceived

benefits/barriers to exercise questionnaire

Garcia et al. (1995), exercise norms, and social

Physical activity, support-interpersonal benefits and variables scale, Garcia barriers of action, et al. (1995), self-efficacy,

Randomized controlled trial activity-related affect, interpersonal (2004), competing influences, and situational influences preference profile,
Differences in all HPM constructs, except activity-related affect and social influences, were significant between baseline and follow-up measurements $(P<0.01)$. Adolescents in the intervention as compared to the control group were placed in action (70\%) or preparation (30\%) stages at follow-up. Moreover, the results revealed that competing preferences, social norms, role models, and commitment to action plan can significantly predict PA behavior $(P<0.001)$. The model accounted for $22.5 \%$ of the variance in PA to a plan of actionplanning for exercise scale, Pender et al. (1995), Recall PA-child/adolescent activity log, Garcia et al. (1997), and time of PA-weekly physical activity scale, (developed by the researchers) activity-related affect-Robbins et al.

165 adolescents old from high schools in Iran demands and Pender et al.(1995),

—situational

influences options, Pender et al. (1995), 


\section{Continued}

To identify and document factors influencing the

Mutulei

(2013), Kenya intermittent

preventive

treatment in

pregnancy

(IPTp2) + uptake

To describe and

identify the

Bhandari, P. predictors of

and Kim, M. health-promoting

(2014), Korea behaviors in

Nepalese migrant workers in Korea
Socio-demographic and economic

Personal attributes, quality of services,

attributes, knowledge health education

Cross-sectional perceptions about a survey

disease, and

health-promoting

behaviors

Perceived health

status, perceived design self-efficacy, and health-promoting behaviors intervention-standard

Perceived health status-a single item Question (n.d), perceived health competence scale (Smith, Wallston, \& Smith, 1995), and health-promoting ance, and perceptions about survey questionnaire (developed by the researcher)
$37.2 \%$ participants who had obtained less than IPTp2 and 53.5\% who accessed IPTp2+ reported receiving support from their partners towards Antenatal Care (ANC) visits, the relationship between the uptake of IPTp services and self-reported risk-perception was not significant, the relationship between the uptake of IPTp and perceived seriousness of 278 pregnant malaria infection during at the 24th week pregnancy was not or more of gestation, aged significant, perception about the duration suggesting up to $95 \%$ between 15 and 49 years in Kenya IPTp significantly associated with the duration taken at the health facilities before receiving services $(P=$ 0.000 ), and the attitude of most providers at the ANC facilities $99 \%$ chance that the uptake of IPTp significantly associated with perceived attitudes of providers towards pregnant women attending ANC clinics $(P$ $=0.000$ ) self-efficacy-perceived behaviorshealth-promoting lifestyle profile II (HPLP II) (Walker \& Hill-Polerecky, 1996)
Spiritual activity was the highest reported health-promoting behavior, whereas physical activity was the least practiced behavior, and

169 Nepalese immigrants workers in Korea self-efficacy was the only significant predictor of health-promoting behavior $(B=0.22, P<$ 0.05) 
To examine

facilitators and

barriers that

migrant women

Tuzcu, A. and

Bahar, Z

(2014), Turkey to breast

self-examina

clinical breast examination, and

mammography phenomeno- Perceived barriers, logical perceived

qualitative (Focus group method)

perceived

facilitators, and

health-promoting

behaviors
Interview

$\begin{array}{ll} & 39 \text { migrant } \\ \text { Interview } & \text { bomen aged } \\ \text { between } 20-57 \\ \text { years in Turkey }\end{array}$

Three main themes were emerged as a result of data analysis: 1) knowledge and awareness about breast cancer; 2) personal factors; and 3) medical service provider and social environment. Also the results showed that $\mathrm{HBM}$ and HPM were effective in explaining barriers and facilitators toward participation of women in screening behaviors. Additionally, lack of information, indifference, and cultural factors are the most important barriers of women

Significant differences between health-promoting behavior and student's age,

To determine health promoting

Shaheen et al. (2015), Jordan behaviors of

Cross-sectional university students in Jordan design and factors influencing them
Health-promoting behaviorsHealth-Promoting Lifestyle Profile II (HPLP II) (Walker \& Hill-Polerecky, 1996)
525 university gender, employment students receiving status, family income, education from university type, and faculty two governmental type $(P<0.01)$, significant and one private differences between males

universities in and females on health Jordan responsibility and interpersonal relations, stress management, and spiritual growth $(P<0.05)$
To determine the knowledge of and Grace, C. and compliance with Sandra, E. standard (2016), Nigeria precautionary measures among nurses
Cross-sectional descriptive design

Knowledge and compliance
Knowledge-five questions (yes/no) answers (developed by working in the researchers) and Madonna compliance-4-items University Likert scale (developed by the researchers) in Nigeria
Knowledge of respondents and their compliance with standard precautionary measures was above average. Majority of the Teaching Hospital nurses (80\%) comply with both medical and surgical asepsis 


\section{Continued}

\begin{tabular}{|c|c|c|c|c|c|c|}
\hline $\begin{array}{l}\text { Hussein et al. } \\
\text { (2016), Egypt }\end{array}$ & $\begin{array}{l}\text { To assess the } \\
\text { effect of } \\
\text { application of } \\
\text { Pender's health } \\
\text { promotion model } \\
\text { on management } \\
\text { of hypertension } \\
\text { among adults in } \\
\text { rural area }\end{array}$ & $\begin{array}{l}\text { Quasi } \\
\text {-experimental } \\
\text { design }\end{array}$ & $\begin{array}{l}\text { Individual } \\
\text { characteristics and } \\
\text { experiences, } \\
\text { behavior-specific } \\
\text { cognitions and } \\
\text { affect, and } \\
\text { behavioral } \\
\text { outcomes }\end{array}$ & $\begin{array}{l}\text { Personal factors-6 } \\
\text { closed ended } \\
\text { questions, Janet } \\
\text { (2011), prior related } \\
\text { behaviors-Hill-bone } \\
\text { blood pressure } \\
\text { medication } \\
\text { compliance scale, } \\
\text { Kim, Hill, Bone, \& } \\
\text { Levine (2000), } \\
\text { behavior-specific } \\
\text { cognition and affects- } \\
\text { behavior-specific } \\
\text { cognition and affects } \\
\text { scale, Angelina (2012), } \\
\text { health promoting } \\
\text { behavior (behavior } \\
\text { outcome)-health } \\
\text { promoting behavior } \\
\text { scale, Glenn (2010), } \\
\text { and physical } \\
\text { measurements- } \\
\text { anthropometric } \\
\text { measurements and } \\
\text { blood pressure }\end{array}$ & $\begin{array}{l}150 \text { adults with } \\
\text { hypertension aged } \\
18 \text { - } 64 \text { in Egypt } \\
\end{array}$ & $\begin{array}{l}\text { Statistical significant } \\
\text { improvement among the } \\
\text { study group than the } \\
\text { control group at the post } \\
\text { test of health-promoting } \\
\text { behavior }(P<0.05) \text {. The } \\
\text { highest mean score was in } \\
\text { the posttest of nutrition } \\
\text { dimension followed by } \\
\text { medication adherence, } \\
\text { stress management and } \\
\text { physical activity but } \\
\text { smoking had no } \\
\text { statistically significant } \\
\text { improvement }(P<0.05)\end{array}$ \\
\hline $\begin{array}{l}\text { Rahimian et al. } \\
\text { (2016), Iran }\end{array}$ & $\begin{array}{l}\text { To examine the } \\
\text { impact of } \\
\text { performing health } \\
\text { promotion model } \\
\text { intervention on } \\
\text { physical activity } \\
\text { of the health } \\
\text { volunteers }\end{array}$ & $\begin{array}{l}\text { Cross-sectional } \\
\text { design }\end{array}$ & $\begin{array}{l}\text { Perceived benefits, } \\
\text { self-efficacy and } \\
\text { health-promoting } \\
\text { behaviors, behavior, } \\
\text { physical activity, } \\
\text { commitment, } \\
\text { emotion and } \\
\text { situational } \\
\text { influences and } \\
\text { perceived barriers }\end{array}$ & $\begin{array}{l}\text { Perceived benefits, } \\
\text { self-efficacy and } \\
\text { health-promoting } \\
\text { behaviors, behavior, } \\
\text { physical activity, } \\
\text { commitment, emotion } \\
\text { and situational } \\
\text { influences. and } \\
\text { perceived } \\
\text {-international } \\
\text { physical activity } \\
\text { questionnaire (IPAQ) } \\
\text { (n.d) }\end{array}$ & $\begin{array}{l}80 \text { health } \\
\text { volunteers in Iran }\end{array}$ & $\begin{array}{l}\text { Significant difference } \\
\text { between the } \\
\text { mean scores of physical } \\
\text { activity and other } \\
\text { structures of HPM in the } \\
\text { experimental group after } \\
\text { the intervention and its } \\
\text { score before intervention } \\
(P<0.001)\end{array}$ \\
\hline $\begin{array}{l}\text { Khodaveisi } \\
\text { et al. (2017), } \\
\text { Iran }\end{array}$ & $\begin{array}{l}\text { To investigate the } \\
\text { effect of Pender's } \\
\text { health promotion } \\
\text { model (HPM) to } \\
\text { improve the } \\
\text { nutritional } \\
\text { behavior of } \\
\text { overweight and } \\
\text { obese women }\end{array}$ & $\begin{array}{l}\text { Quasi } \\
\text {-experimental } \\
\text { design }\end{array}$ & $\begin{array}{l}\text { Perceived benefits, } \\
\text { perceived } \\
\text { barriers, perceived } \\
\text { self-efficacy, } \\
\text { behavior-related } \\
\text { affect, interpersonal } \\
\text { influences, } \\
\text { situational } \\
\text { influences, } \\
\text { commitment to } \\
\text { action, and } \\
\text { nutritional behavior }\end{array}$ & $\begin{array}{l}\text { Perceived benefits, } \\
\text { perceived } \\
\text { barriers, perceived } \\
\text { self-efficacy, } \\
\text { behavior-related } \\
\text { affect, interpersonal } \\
\text { influences, situational } \\
\text { influences, } \\
\text { commitment to } \\
\text { action and nutritional } \\
\text { behavior-researchers } \\
\text { developed inventories }\end{array}$ & $\begin{array}{l}108 \text { overweight } \\
\text { women visits } \\
\text { hospital clinics in } \\
\text { Iran }\end{array}$ & $\begin{array}{l}\text { Significant differences in } \\
\text { the experimental group } \\
\text { before and after the } \\
\text { intervention in nutritional } \\
\text { behavior, perceived } \\
\text { benefits, perceived } \\
\text { self-efficacy, commitment } \\
\text { to action, interpersonal } \\
\text { and situational influences, } \\
\text { behavior-related affect, } \\
\text { and perceived barriers }(P< \\
0.001)\end{array}$ \\
\hline
\end{tabular}




\section{Continued}

\begin{tabular}{|c|c|c|c|c|c|c|}
\hline $\begin{array}{l}\text { Ayres, C. and } \\
\text { Pontes, N. } \\
(2018), \text { USA }\end{array}$ & $\begin{array}{l}\text { To examine the } \\
\text { factors that may } \\
\text { influence health } \\
\text { responsibility } \\
\text { among } \\
\text { adolescents }\end{array}$ & $\begin{array}{l}\text { Correlational } \\
\text { study design }\end{array}$ & $\begin{array}{l}\text { Health } \\
\text { responsibility, } \\
\text { resilience, } \\
\text { neighborhood } \\
\text { perception, social } \\
\text { support, and health } \\
\text { promoting }\end{array}$ & $\begin{array}{l}\text { Health responsibility } \\
\text {-adolescent lifestyle } \\
\text { profile (ALP-R2) } \\
\text { Hendricks, Pender, \& } \\
\text { Hendricks, (2001), } \\
\text { Resilience-brief } \\
\text { resilience scale (BRS), } \\
\text { Dalen, Wiggins, } \\
\text { Tooley, Christopher, } \\
\text { and Bernard (2008), } \\
\text { Social support-the } \\
\text { multidimensional } \\
\text { scale of perceived } \\
\text { social support } \\
\text { (MSPSS), (Zimet, } \\
\text { Dahlem, Zimet, \& } \\
\text { Farley, (1988), and } \\
\text { neighborhood } \\
\text { perception-perceived } \\
\text { neighborhood } \\
\text { disorder scale } \\
\text { (PNDS), Ross \& } \\
\text { Mirowsky, (2001) }\end{array}$ & $\begin{array}{l}122 \text { adolescents } \\
\text { aged } 13 \text { - } 18 \text { years } \\
\text { in an urban } \\
\text { setting in USA }\end{array}$ & $\begin{array}{l}\text { Significant relationship } \\
\text { was found between health } \\
\text { responsibility and health } \\
\text { promoting behaviors }(r= \\
0.733, P<0.001) \text { and } \\
\text { between health } \\
\text { responsibility and } \\
\text { neigborhood perception }(r \\
=0.163, P<0.01) \text {. } \\
\text { No relationships were } \\
\text { found between the } \\
\text { dependent variable of } \\
\text { health responsibility and } \\
\text { the independent variables } \\
\text { of resilience and social } \\
\text { support in this population }\end{array}$ \\
\hline
\end{tabular}

